\title{
A ESCRITA FEMININA JAPONESA: UM BREVE PANORAMA DAS PRODUÇÕES CLÁSSICAS ÀS CONTEMPORÂNEAS ${ }^{1}$ \\ THE JAPANESE WOMEN'S WRITING: A BRIEF SURVEY FROM CLASSIC TO CONTEMPORARY WORKS
}

\author{
Joy Nascimento Afonso ${ }^{2}$ \\ Priscila Yamaguchi Leal
}

Resumo: Quando observamos a produção literária japonesa contemporânea notamos que as publicações de mulheres têm se quantificado proporcionalmente a dos homens. Mas qual têm sido as características dessas produções? Há características em sua escrita que as distinguem dos homens? Neste trabalho, nosso objetivo é disponibilizar um panorama sucinto dessas obras de autoria feminina vertidas para o português e entender baseando-nos na produção das autoras Banana Yoshimoto e Hiromi Kawakami quais são as características dessa escrita feminina e como ela se dá no âmbito dos estudos japoneses. Tentando entender essa produção não somente como um reflexo da sociedade atual japonesa, mas também como forma de ver o homem universal em seu processo continuo de se entender.

Palavras-chave: Yoshimoto Banana, Kawakami Hiromi, escrita feminina, literatura japonesa contemporânea, identidade feminina.

Abstract: When we look at contemporary Japanese literature, we notice that publications of women have been quantified to the proportion of men. But what are the characteristics of these productions? Are there features in their writing that distinguish them from men? At this work,

1 Artigo submetido em 21/09/2018 e aprovado em 09/12/2018.

2 Doutoranda em Literatura Comparada e Professora Assistente Mestre no Departamento de Letras Modernas, Área de Japonês, da Universidade Estadual Paulista "Julio de Mesquita Filho" (UNESP), Assis, Brasil; joynafonso@gmail.com (ORCID iD: http://orcid. org/0000-0002-0994-5524).

3 Graduanda em Letras - Português/Japonês pela Universidade Estadual Paulista "Júlio de Mesquita Filho" - Faculdade de Filosofia, Ciências e Letras de Assis (UNESP - FCL/Assis, Assis, Brasil; priscilayamaguchileal@gmail.com (ORCID iD: http://orcid.org/0000-0002-0415-2461). 
our goal is to provide a brief overview of the female authors translated into Portuguese and understand, based on the production of the authors Banana Yoshimoto and Hiromi Kawakami, what are the characteristics of women's writing and how it's done within the Japanese studies. Trying to understand this production not only as a reflection of the current Japanese society, but also as a way to see the universal man in his continuous process of self-understanding.

Keywords: Yoshimoto Banana, Kawakami Hiromi, feminine writing, Japanese contemporary literature, female identity.

\section{Introdução}

Quando observamos a produção literária japonesa contemporânea notamos que as publicações de mulheres têm se quantificado proporcionalmente a dos homens. Estas são reconhecidas internacionalmente por meio de prêmios literários, fator este que tem levado o mercado editorial ocidental a traduzir muitas dessas obras.

Mas quais são as características dessas produções? Há características em sua escrita que a distingue dos homens? E ainda quem são as escritoras e obras que já foram traduzidas para a língua portuguesa? Neste trabalho, nossa proposta é disponibilizar um panorama sucinto dessas obras de autoria feminina vertidas para o português. Nosso percurso inicia-se no Período Clássico, período no qual as damas da corte de Heian, além de desenvolverem uma escrita feminina que deu origem ao Hiragana, produzem as primeiras obras consideradas romances. Já no Período Meiji as mulheres retomam a visibilidade no âmbito literário, em um momento propício visto que elas contavam com mentores, como é o caso da escritora Ichiyô Higuchi. No pós-segunda guerra mundial destacamos a figura de Sawako Ariyoshi, com traços de uma literatura engajada de crítica social. Para finalizar, passamos para as autoras contemporâneas Banana Yoshimoto e Hiromi Kawakami, momento em que analisaremos a questão da escrita feminina propriamente dita em suas características.

\section{A escrita e o período clássico}

A produção de autoria feminina japonesa perpassa em muitos momentos pela própria organização da escrita no país. Em torno do século V, os japoneses passam a ter os primeiros contatos em massa com a escrita chinesa por meio de tratados oficiais e símbolos religiosos. Esta escrita contou com a contribuição de "chineses e coreanos radicados no Japão [...] que eram requisitados pela corte para a elaboração de textos oficiais" (SUZUKI, 1985, p.56). Dessa forma a escrita japonesa surge baseada na grafia chinesa, isto é os ideogramas chineses passam a ter sons próprios da língua nipônica.

Foram necessários vários séculos até a escrita ideográfica se prestar a expressar a língua japonesa, [...] Tendo sido assimilada por homens da nobreza, foi por suas mãos reproduzida em preceitos legais, ordens imperiais, comunicados oficiais, 
escritos em estilo chinês. Com o tempo, os ideogramas vão sendo adaptados à língua japonesa até poderem expressar o espírito japonês, como ocorreu com os poemas do séc. VIII. (Idem, p.58).

No início do período Heian (794-1192), baseando-se nos ideogramas, desenvolvese paralelamente dois sistemas de escrita. Uma criada pelos Bonzo, que os auxiliava na leitura dos sutras sagrados chamada de katakana, e a outra pelas damas da corte, em estilo cursivo, denominado hiragana.

\subsection{Período clássico: primeiras produções}

Entende-se por período clássico os anos que antecedem a instauração Meiji, ou seja, até fins do Período Edo (1603-1868). É neste período de acesso às letras e consequentemente de desenvolvimento de uma escrita feminina - onnamoji (letra mulher), que surgem as primeiras obras de autoria feminina. Dentre as de maior destaque e, que possuem tradução para a língua portuguesa, temos do inicio do século XI a obra O livro do travesseiro (Makura no Sôshi, 2013 para o português) escrito pela dama da corte Sei Shônagon, que inclui cerca de 300 ensaios em que ela registra "ao sabor da pena, as suas perspicazes impressões e observações referentes à natureza, à vida da corte, sobre o mundo que a rodeia" (YOSHIDA, 1999, p.64).

A segunda obra mais conhecida é a narrativa ficcional Genji Monogatari ( $O$ Romance de Genji - trad. português lusitano, 2008), da também dama da corte Murasaki Shikibu, obra que foi concluída por volta de 1008 e possui 54 tomos. A obra através dos vários relacionamentos amorosos do príncipe Hikaru Genji e de seus descendentes aborda "as 'questões existenciais, religiosas ou filosóficas enfrentadas pelo mundo da aristocracia' em que a autora vivia" (YOSHIDA, 1999, p.65), descrevendo de forma minuciosa ambientes e trajes da época.

Das obras destacadas observamos que a temática volta-se para os ambientes internos da vida palaciana e do dia a dia das damas da corte que acompanhavam a consorte real, vivendo em função da vida dos soberanos, sob forte influência religiosa.

Do período clássico até o período Meiji a produção de autoria feminina sofreu certo "silenciamento" devido ao advento do período Kamakura, conhecido como a época dos samurais. O poder centralizava-se na figura masculina que era reconhecida pela força militar e pela extensão das propriedades. Além disso, a "herança que era dividida igualmente entre todos os filhos até aproximadamente o século XIV, passa a privilegiar apenas o primogênito, evitando, assim, o esfacelamento das propriedades e o consequente enfraquecimento do poder econômico" (YOSHIDA, 1992, p.63), deixando à incumbência da mulher o dever de gerar um filho homem para dar continuidade à linhagem da família, restringindo a figura feminina somente ao âmbito doméstico, subordinada ao homem. Essa ideia é reforçada pelo budismo que influenciou os grandes governantes do Japão, e também pelo pensamento do ryôsai-kenbo (boa esposa, mãe 
sábia) "a mulher devotada exclusivamente ao lar, que advém com Reforma Meiji, em 1868" (Idem, p.64), pensamento esse que nos permite identificar a imagem que se tem cristalizada até os dias de hoje da mulher japonesa submissa e frágil.

\section{Período Meiji: literatura feminina viabilizada por mentores}

Do período Meiji (1868- 1912) destacamos a escritora Ichiyô Higuchi (18721986). De prenome original Natsu, foi a quarta filha de uma típica família em decadência diante do novo regime político e social da era Meiji. Ichiyô inicia sua produção literária instruída por um mentor, o mestre Nakarai Tôsui, que a orienta a popularizar sua forma de escrita a fim de atingir a grande massa por meio dos periódicos, muito populares naquele período.

Sobre este estilo que mesclava o clássico ao popular, Takehara (1993) destaca que:

Em um estilo neoclássico, que a aproximava da literatura clássica japonesa, criou textos com estrutura sintática complexa, muitas vezes fora da norma, obedecendo ao fluxo da consciência e escrevendo em linguagem falada, veloz, com pontuação pouco clara e parágrafos bastante longos (TAKEHARA, 1993, p.20).

A fim de ajudar os jovens aspirantes a romancistas, seu mentor funda o periódico Musashino, no qual publica a primeira obra de Higuchi - Yamizakura (1982, Flor de cerejeira na escuridão) que passa a assinar com o pseudônimo que a tornaria conhecida. A revista, no entanto, teve somente três números publicados. Segundo Hagino (2007) a fundação da revista por Nakarai tinha por objetivo tornar Ichiyô reconhecida, visto que seu mentor nutria sentimentos profundos pela escritora.

Sobre as escolhas de Higuchi como escritora, Tetsuya Hatori (2001) destaca que a autora possuía características que ele chama de "anti-carreirista" por escrever sobre o que lhe convinha e não sobre temas que possivelmente lhe trariam dinheiro. Dedicandose a literatura não havia como sustentar sua família, o que a levou à falência e morte aos 24 anos por tuberculose.

Em português temos o conto Caminhos Opostos (Wakaremichi) que está inserido na coletânea de contos da Era Meiji organizado pelo Centro de Estudos Japoneses da USP em 1995, e o romance Nigorie (Enseada de águas turvas) traduzido e analisado por Rika Hagino (2010) em sua dissertação de mestrado.

\section{Período Pós-Segunda Guerra: literatura feminina socialmente engajada}

Após o fim da Segunda Guerra Mundial até início dos anos 1990, momento no qual o país se via mergulhado em tristeza, surgem mulheres que se propõe a refletir socialmente sobre a guerra, suas perdas e a sociedade de Shôwa (1926-1945). É neste contexto que se insere a autora Sawako Ariyoshi (1931-1984). 
Apesar de nascida no Japão, desde muito cedo muda-se com seu pai para Java na Indonésia, e mesmo quando retorna ao país de origem torna a mudar-se, dessa vez indo para os Estados Unidos. Mais tarde é convidada a estudar na China, onde posteriormente retorna e adquire sua formação em Nestorianismo pela Universidade de Pequim em 1965.

A autora é reconhecida por seu engajamento social devido aos temas discutidos em suas obras, como poluição, preconceito racial, miséria, contaminação de alimentos e tabus sócio-político japoneses de armamento e problemas enfrentados pelos idosos. No que diz respeito aos problemas femininos, a autora estava décadas à frente.

Uma de suas obras mais conhecidas é Hanaoka Seishû no Tsuma (The Doctor's Wife, 2004 para o inglês) uma ficção histórica baseada em fatos reais que discute a relação entre a mãe e a esposa do médico Seishû Hanaoka (1860-1835), médico que utilizou a anestesia antes de qualquer outro país como procedimento científico.

Em português temos a antologia de contos O Canto da Terra (Jiuta- $1956 \mathrm{em}$ japonês) de 1994, que foi a primeira obra lançada pela autora, obra que the rendeu o prêmio Akutagawa de autora revelação em 1956. Neste conto o pai e sua filha tentam manter viva uma arte tradicional que está desaparecendo. Isto porque o título deste conto remete a arte tradicional do "canto local" de uma região, tocado em koto, normalmente apresentado por um grupo de deficientes visuais no Período Edo.

\section{Período contemporâneo: uma nova geração de escritoras}

No final do Período Meiji apesar da política do ryôsai-kenbo (boa esposa e mãe sábia), de mãe, casada e dona de casa, que tinha como finalidade reforçar "modelos de comportamento considerados exemplares" (FUJINO, 2002, P.105), surge o que ficou conhecido como Onna no Jidai (Período Feminino), momento que a mulher japonesa, influenciada pelos ideais feministas ocidentais que eram disseminados por várias revistas de moda, passa a exercer de fato seu poder na sociedade. A mulher passa a escolher entre se casar ou continuar morando com os pais, trabalhando e com isso sendo financeiramente independente. As que decidem se casar e que não raramente o fazem mais tarde, passam a opinar na formação do lar, decidindo entre ter ou não filhos. O retorno da política de ryôsai-kenbo nos anos 1960 destaca ainda mais o trabalho de escritoras como Taeko Kono (1926), Takako Takahashi (1932- 2013), e Yumiko Kurahashi (1935-2005), autoras relevantes no período, atuaram como eco de vozes que resistiam a esse ressurgimento. Foi por meio da literatura que cada uma dessas escritoras demonstrou, em suas protagonistas e histórias de vida, que as mulheres não precisavam se formar cristalizadas como "boa esposa e mãe sábia".

É importante perceber que as escritoras dos anos de 1960 e as que se destacarão nos períodos subsequentes, configuram-se em uma condição financeira e intelectual privilegiadas. Suas formações acadêmicas em escolas de alto padrão e as oportunidades de viajar e conhecer outras culturas, parecem ser uma característica comum a essas 
autoras. Em um contexto de independência financeira e consequentemente intelectual, é que surgem muitas escritoras com princípios feministas - e aqui compreendemos por princípios feministas o que concerne a "todo gesto ou ação que resulte em protesto contra a opressão e a discriminação da mulher, ou que exija a ampliação de seus direitos civis e políticos, seja por iniciativa individual, seja de grupo" (DUARTE, 2003) - declarados em sua escrita. Para análise sob essa perspectiva escolhemos duas autoras traduzidas para a língua portuguesa: Banana Yoshimoto e Hiromi Kawakami.

Banana Yoshimoto, ou Mahako Yoshimoto, nasceu em Tóquio em julho de 1964, filha do famoso crítico literário e poeta Takaaki Yoshimoto e irmã da desenhista de mangá Haruno Yoiko, a escritora cresceu em uma família vista como liberal. Ainda com 16 anos resolveu sair de casa para morar com o namorado e na Universidade de Tóquio (Nippon University), onde cursou Artes, abriu mão da ajuda financeira familiar indo trabalhar de garçonete em uma lanchonete, onde se inspirou para escrever seu primeiro romance Kitchen (Kichin - A Cozinha, 1988), traduzido para o português do italiano em 1995.

Quanto ao seu pseudônimo - banana, "ora ela explica que o escolheu por gostar de beleza das flores de bananeira, ora afirma que foi por seu lado engraçado e andrógino" (LECLERQ, 2006, p.242). Já neste aspecto a dualidade de signos que irá se refletir na obra de Yoshimoto Banana é sentida.

O romance Kitchen (formado por dois contos) foi sua primeira obra traduzida para o português no Brasil. Pelo conto, recebeu o prêmio Kaien para escritores iniciantes em 1987. Kitchen foi lançado em forma de romance com a inserção do conto Moonlight Shadow (Mûn raito shadô) que recebeu o Prêmio Izumi Kyôka em 1988, por abordar a temática do mistério e da morte. O sucesso do romance foi tamanho que os críticos passaram a chamar esse boom de "Bananamania", tendo em vista que a obra foi aclamada não somente pelo público como também pela crítica, que passava a sentir uma produção escrita de autoria feminina discutindo temas tabus como o ato de transvestirse ou novas concepções familiares de forma muito característica. A obra também foi adaptada para a televisão japonesa em 1990 por Morita Yoshimitsu e para o cinema por Ho Yim, em Hong Kong, em 1997.

Em língua portuguesa lusitana temos ainda a tradução das obras Adeus Tsugumi (Tsugumi, 2004), A ultima amante de Hachiko (Hachiko no saigô no koibito, 2005), Arco-íris (Niji, 2006) e Lua de mel (Hanei môn, 2007), todas publicadas pela editora Cavalo de Ferro. No Brasil, a obra foi publicada em 2015, traduzida pela professora Lica Hashimoto.

Sobre o estilo de escrita da autora temos em língua portuguesa dois artigos que abordam a produção de Banana, em um deles é discutida a obra publicada no Brasil Kitchen (A Cozinha) em 1995. Segundo Yoshida (1990) o estilo da autora é moderno e despretensioso, não deixando de provocar polêmica entre os críticos, "mas quase todos são unânimes em reconhecer que Banana foi capaz de captar, na medida exata e de maneira lúcida, ofeeling da jovem geração japonesa" (p.58). 
Para Leclerq (2006) as obras de Banana versam principalmente sobre: a perda, o luto, a família (embora não no formato tradicional), a sexualidade, o suicídio, a identidade e a solidão. E suas histórias "tratam geralmente de uma busca de si mesmo, do sentido da vida, de uma mudança na vida, frequentemente após um trauma, e levando à transformação [...] A literatura de Yoshimoto fala de desencanto, não de desespero" (p.242). Baseada nesta temática a autora cria personagens que precisam da ajuda externa para superar suas dores e traumas.

Quanto à atual produção de Banana, a autora publica de duas a três obras em média por ano, ressaltando um contexto de apoio financeiro e intelectual para suas obras, visto que publica pela mesma editora há mais de dez anos. Outro sinal de que o estilo da autora está mais amadurecido e firmado são o número crescente de seus romances traduzidos para outras línguas que a tem tornado conhecida também em contexto internacional devido aos vários prêmios recebidos.

No que diz respeito às características de sua escrita, notamos de forma geral alguns temas recorrentes em suas obras mais recentes. Como observa Leclerq, as obras de Banana ressaltam processos que levam à transformação. Sob nossa ótica muito desses processos refletem processos de amadurecimento, de entendimento de si mesma frente às mudanças sociais e perdas familiares ou, ainda, processos de recomeço como sociedade.

Em se tratando de retomar a vida e encontrar perspectivas para o futuro, é possível encontrar essa abordagem em Kitchen (1995), na qual a protagonista, Mikage, se vê órfã na idade adulta e para recomeçar tem como apoio uma família que não segue a formação comum e com quem não tem laços sanguíneos. Em Arco-íris (2006), a jovem Eiko parte sozinha para Tóquio, onde inicia uma nova fase da sua vida após a morte da sua mãe e da sua avó. Em Tóquio trabalha no Arco-íris, um restaurante polinésio. É no restaurante que a jovem acaba por se envolver de forma involuntária nos problemas e confusões do casal de proprietários. Porém, antes que os dramas alheios a sufoquem decide fazer a viagem dos seus sonhos, e assim parte para o Taiti. Em ambas as obras uma nova concepção familiar - a família de Eriko (Kitchen) e a "família" do restaurante Arco-íris tornam-se a base do processo de recomeço para as protagonistas que, para encontrarem perspectiva para o futuro, enfrentam a dor aceitando ajuda e apoio de estranhos.

Há ainda a retomada da vida tendo como pano de fundo tragédias de âmbito nacional, como é o caso da obra Lake (Mizûmi, O Lago, 2005) na qual a protagonista, após a morte de sua mãe, muda-se para a capital Tóquio desejando tornar-se uma artista gráfica, mas ao contrário disso passa dias observando as ruas e conhece um rapaz com quem tem um romance, e que havia sofrido um trauma na infância, indo com ele visitar alguns amigos que vivem uma vida reclusa junto a um lago, local esse que servirá como base para estranhos cultos religiosos revelando o real problema do passado de seu namorado. A obra faz referência a seita Aum Shinrikyo (Ensinamento da Verdade Suprema) que em 1995 efetuou um ataque com gás sarin ao metrô de Tóquio matando 12 pessoas e ferindo 6.000 de forma indireta, tornando-se o pior atentando terrorista da 
história do Japão. Os membros da seita em sua maioria jovens de classe média e alta que estudavam em grandes universidades prezavam a vida ascética e reclusa propagando rituais de purificação. Nesse caso, um passado misterioso e mal compreendido pode revelar um lado oculto e, por vezes perigoso, da alma humana.

Em Sweet Hereafter (Sûito Hiâfutâ, Doce Depois, 2011) após sobreviver a uma experiência de quase morte, um acidente de carro que leva seu noivo à morte, a protagonista da obra tem a visão do mundo pós morte, onde se encontra com seu pai já falecido e com o cachorro que teve no jardim de infância. Após acordar do coma, sentindo que a vida real não mais existe, ela passa a ver e a conversar com fantasmas. Ela viaja para Okinawa a fim de melhor entender tal plano espiritual e tudo o que the aconteceu, entrando em uma misteriosa viagem entre os dois mundos: real e pós-morte. Tendo como pano de fundo a catástrofe de fevereiro de 2011, a autora retoma por meio da religião e da espiritualidade o processo de reconstrução da vida após um grande abalo social, tentando trazer ao leitor conforto por meio da leitura da obra.

Dessa forma, tanto em Lake (Mizûmi, O Lago, 2005) quanto em Sweet Hereafter (Sûito Hiâfutâ, Doce depois, 2011) novamente a temática da morte, da partida, de entendimentos dos grandes traumas sociais como reinício, como forma de recomeço frente a uma tragédia de âmbito nacional é proposta como solução, como forma de conforto. Nas duas obras retomar lembranças e ficar na linha tênue entre o mundo dos vivos e dos mortos significa entender que quem se ama às vezes se vai para sempre porém, sempre se pode ter contato com eles por meio do sentimento que é eterno e, entendendo a morte, sentir-se mais esperançoso para retomar a vida.

Hiromi Kawakami, ou Hiromi Yamada, nasceu em Tóquio em 1 de abril de 1958, graduada em Ciências Biológicas na Universidade Feminina de Ochanomizu (Ochanomizu University). Iniciou na literatura utilizando seu nome de nascença Hiromi Yamada, na revista NW-SF em 1980, com o conto Sôshimoku (Diptera em inglês). Teve sua reestreia no mundo literário, já como Hiromi Kawakami, com a coletânea de contos Kamisama (The God of Bears, 2011), em 1994. A autora recebeu o prêmio Akutagawa em 1996 por Hebi o Fumu (Tread on a Sneake, 1996), e o prêmio Tanizaki em 2001 por $A$ Valise do Professor (Sensei no Kaban), vertido e publicado no português por Jefferson José Teixeira. Em 2010 também para o português, teve traduzido e publicado Quinquilharias Nakano (Furudoku Nakano Shoten), pelo mesmo tradutor. Para o português lusitano, além de Sensei no Kaban (traduzido como Os Anos Doces), foi traduzido também Manazuru (Manazuru), com o título mantido como o original. Ambos os livros publicados pela editora Relógio D’Água.

O livro de estréia da autora no Brasil, Quinquilharias Nakano (Furudôgu Nakano Shôten, 2010) conta as memórias de Hitomi do período que trabalhou na loja do senhor Nakano. A narradora homodiegética nos conta que conheceu Takeo, um jovem que tem aproximadamente a sua idade e é uma espécie de "faz tudo" na loja. É também na loja que conhece Masayo, irmã do senhor Nakano, que exerce a profissão de artista plástica. Durante o tempo trabalhado na loja de quinquilharias, Hitomi e Takeo tem 
um envolvimento romântico, porém não se torna um relacionamento sério. Boa parte da narrativa é composta pelo envolvimento dessas duas personagens, todavia, também observamos as relações que ocorrem entre as personagens que constroem essa rememoração.

É característico neste e em outros livros da autora a retomada do passado como uma construção da memória, que posta em ordem escrita torna-se ferramenta para um autoconhecimento e perspectiva para o futuro, como vimos que é prática exercida também por Banana e alguns de seus livros. Não há tom de saudosismo, mas sim de busca e superação. Não à toa, a narrativa de Hitomi termina quando a personagem já está empregada em outro local e reencontra seus companheiros na nova loja do senhor Nakano, agora um antiquário. A loja parece ser a ambientação que atua como reflexo das relações que se dão entre as personagens, um local simples e com peças que não valem tanto quanto as de um antiquário. As relações que se constroem parecem todas acabarem da mesma forma que acaba a loja, em um processo de lento desgaste. Já as relações que não tem um fim propriamente dito passam por um processo de amadurecimento, de melhora, como a de quinquilharias para antiquário.

O segundo livro publicado no Brasil, A Valise do Professor (Sensei no Kaban, 2012) tem por início o reencontro de Tsukiko e seu antigo professor do ensino médio, Harutsuna. A maior parte do livro versa sobre os encontros entre Tsukiko e seu professor no bar de Satoru. A atenção aos detalhes é o que dará o tom da narrativa, assim como as reflexões de Tsukiko quanto ao seu relacionamento com o professor, a qual não possui nomenclaturas explícitas e nem parece ter a necessidade de tal. Uma característica que pode ser vista como razão para destaque na escrita de Kawakami é o tratamento natural dado a situações que são tratadas socialmente em tom de polemismo. E, apesar da relação sexual entre os dois personagens não ser o centro desse envolvimento, a autora trata com suavidade, em tom romântico sem pedantismo, uma sensualidade que perpassa seus encontros. Com tamanha naturalidade que, talvez, não fosse de se esperar.

Manazuru (2012 na edição lusitana, 2001 na nipônica) é o livro que contará as constantes idas de Kei à cidade litorânea de Manazuru e o único vestígio que seu desaparecido marido deixou: a palavra escrita em um diário. Os momentos apresentados com certa recorrência remetem a situações do passado que giram em torno das relações familiares: as lembranças do seu marido e dela mesma, o relacionamento com sua mãe e com a filha que, assim como ela, também foi deixada. A personagem parece passar por uma busca de sua identidade e um encerramento quanto à memória de seu marido, deixando em aberto se tanto uma questão quanto a outra são resolvidas. E essa parece ser uma característica das duas contemporâneas aqui citadas. O que parece algo a ser solucionado, concluído de alguma maneira, causa uma impressão incerta de concluso, mas a certeza fica a cargo daquele que lê.

Não somente as protagonistas de seus livros como as personagens em geral, tanto as de Kawakami como as de Banana, representam mulheres que não identificam a imagem de submissa e frágil que costumeiramente é dita como a mulher japonesa, que 
segundo Yoshida (1992) é "uma tendência comportamental de determinados períodos" (p. 63) e acabou por cristalizar-se na imagem da mulher padrão japonesa. É feita a quebra de paradigmas tais como relacionamento entre pessoas de níveis hierárquicos e de diferentes idades, como em $A$ Valise do Professor; ou a constituição de uma família não tradicional, como em Kitchen; as formas de lidar com a perda e as emoções que envolvem aqueles que ficam, utilizando a escrita e a rememoração, forma pela qual suas histórias chegam até nós. Outra característica que identificamos é a da fala dessas personagens em torno do sentimento tão difundido na cultura literária mundial: o amor que é uma fala de naturalidade. A naturalidade que torna a perda desse componente em suas vidas uma situação a ser vivida. É o como viver que dará vida à suas histórias.

\section{Escrita: feminino e identidade}

A literatura de autoria feminina (ou escrita feminina) e seus temas podem ser postos como aqueles que possuem "um tom, uma dicção, um ritmo, uma respiração próprios" (BRANCO, 1991, p. 13). Ao adjetivar essa escrita como "feminina" aqui não falamos apenas daquilo que é escrito pelo feminino, por mulheres, mas sim algo que tem de relativo às mulheres. Em sua própria forma, se pensarmos na sua construção linguística. Segundo Ostermann \& Fontana (2009) na introdução da obra Linguagem, gênero, sexualidade: clássicos traduzidos, "gênero não é algo com que se nasce, nem algo que se possui, mas algo que se faz" (p. 15) esmiuçando propriamente a ideia de gênero, que é para Judith Butler "algo que se desempenha por meio da linguagem" (Idem, p. 15). Da mesma forma para Duarte (2003) já no séc. XIX a escritora Nísia Floresta Brasileira Augusta (1810-1885) antecipava a noção de gênero ao dizer que mulheres "são diferentes no corpo, mas isto não significa diferenças na alma" (p. 153), o que os linguistas farão na década de 1970 e suas subsequentes é dizer que também por meio do comportamento linguístico encontramos vestígios dessas diferenças que não tem fundo biológico.

Por esse motivo trazemos à luz dos estudos literários as características vistas nas autoras contemporâneas japonesas. Porém, mantendo em mente que as características dessa literatura não se encontram em uma nacionalidade, mas sim em escritas que revelam uma identidade. Segundo Magalhães (2004), em suas considerações sobre as identidades femininas enunciadas por mulheres, a autora búlgaro-francesa Julia Kristeva elucida aquilo que seria "uma espécie de milenar memória feminina que diz respeito às respostas que as mulheres, apesar de toda a sua diversidade, deram à vida" (p. 15), o que justificaria por consequência uma identidade feminina. É o que, no caso de poetisas brasileiras, Branco (2004) chama de "um diálogo de surdas" (p. 97) e transferimos para um diálogo universal na "linguagem das mulheres" 4 .

4 Robin Lakoff em "Linguagem e Lugar da Mulher" (1973) traduzido por Adriana Braga e Édison Luis Gastaldo, publicado na coletânea Linguagem. Gênero. Sexualidade: Clássicos traduzidos em 2010 pela editora Parábola. Trata de um efeito geral da "linguagem das mulheres" e descreve o que nos parece 
Enquanto pensamos em escrita feminina não há como não pensar no porque essa escrita se dá, visto que desde anos atrás observamos dificuldades na produção feminina de todas as sociedades. Apesar de notarmos o aumento na produção de autoria feminina nos dias atuais, assim como a recepção junto ao público e a crítica, entendemos que essa posição foi alcançada com muito esforço não somente por escritoras feministas, mas por todas aquelas que buscam manter o papel de liberdade da escrita, talvez da melhor maneira que se possa fazer: escrevendo.

Baseando-nos neste papel exercido pela literatura que possibilita que a voz feminina seja ouvida, observamos uma identidade própria desta escrita, que se dá no caso das autoras japonesas escolhidas, por meio das temáticas abordadas em suas obras: a busca de entender a si mesma diante dos processos, das transformações propiciadas pela vida ou pela morte. A escrita dessas mulheres revela as características não somente das orientais, mas sim de mulheres que ao escrever descrevem a vida com suas dificuldades e dores de forma delicada, tocando em temas como o sofrimento e a perda. Dessa forma, revelam não somente temas universais, sentidos por todo ser humano, mas também a delicadeza da poesia japonesa sentida em sua escrita, por meio da escolha de vocabulário. Escolha essa que é vista muitas vezes como simplista demais, e muitos críticos ainda veem essas produções como uma leitura superficial e dramática, mas que na realidade exprimem uma das maiores características da cultura japonesa: a beleza da simplicidade, do instante.

Uma cultura que busca a perfeição nos detalhes da simplicidade devido à forte influência nas artes do budismo e xintoísmo que remete a natureza sazonal revela-se por meio da escrita de autoria feminina na beleza de um vocabulário que exprima sensações, cheiros, lembranças do dia a dia com a pessoa amada, ambientes domésticos e memórias que fazem referência a morte, ou a um mundo em que a morte não é o fim, mas sim recomeço.

\section{Conclusão}

Com o objetivo de fornecer um panorama geral das produções de autoria feminina vertidas para língua portuguesa, perpassamos as obras japonesas nos deparando com uma quantidade considerável de produções, ressaltando que desde os clássicos até a contemporaneidade as mulheres têm se mostrado presente. Observando a produção de escrita feminina identificamos algumas características nessa "escrita" que resvalam não somente na questão de gênero, mas sim na forma de abordagem de alguns temas. Para melhor observar essa questão escolhemos as autoras Banana Yoshimoto e Hiromi Kawakami, como mulheres contemporâneas que possuem traços semelhantes em suas obras.

conveniente também às considerações sobre identidade feminina. $\mathrm{O}$ autor afirma que essa linguagem "significa tanto a linguagem restrita ao uso das mulheres quanto a linguagem descritiva das mulheres simplesmente" e pontua os efeitos gerados e seus reflexos na posição da mulher nas relações sociais. 
Ambas reconhecidas no exterior devido aos prêmios recebidos e pelo reconhecimento da crítica literária tendo em vista a recepção junto ao público leitor, sua notoriedade também é notada pela intensa produção escrita que as autoras acumulam, o que revela um momento propício para as produções literárias de autoria feminina.

Baseando-nos principalmente em obras traduzidas para a língua portuguesa notamos que ambas, por meio de um vocabulário simples, direto, mas minuciosamente escolhido abordam temas como a morte e os relacionamentos familiares sob uma ótica delicada e cheia de espiritualidade. O que demonstra não somente características de uma escrita feminina, com a recorrência a temas ligados ao lar, à família, aos relacionamentos e ao corpo feminino, como também revelam uma identidade feminina japonesa notada em uma escrita que faz referências ao clima, às estações do ano e ao misticismo.

Dessa maneira temos autoras que abordam temas universais como a morte, a perda e a dor, mas também, nos possibilita notar a delicadeza e simplicidade típica da cultura japonesa ao abordar esses temas. Elaborar tais questões não significa necessariamente resolução, mas sim dar a chance de se respirar, retomar a vida, lembrar com saudade de quem se ama e principalmente permitindo que a memória seja a base de construção do futuro. Para os leitores, acreditamos que essa escrita enriquece a leitura, promovendo um olhar da cultura do outro como se estivéssemos olhando a nós mesmos.

\section{Referências Bibliográficas}

BRANCO, Lucia Castello. O que é Escrita Feminina. 1 ed. São Paulo: Brasiliense, 1991. Coleção Primeiros Passos, vol. 251.

BRANCO, Lucia Castello. A escrita mulher. In: BRANCO, Lucia Castello; BRANDÃO, Ruth Silviano. A mulher escrita. 2. ed. Rio de Janeiro: Lamparina, 2004. Capítulo 2, p. 97-215.

DUARTE, Constância Lima Duarte. Feminismo e literatura no Brasil, 2003. Estudos Avançados, São Paulo, v. 17, n. 49, p. 151-172, set/dez, 2003.

FUJINO, Yoko. O Corpo Feminino Descoberto: Análise da sereia de Takeuchi Keishû no contexto editorial da Era Meiji. In: Revista de Estudos Japoneses, n. 22, pp. 103 - 111, 2002.

HAGINO, Rika. Hongô Kikuzakachô: Primeiro amor e o percurso até o romance (setembro de 1890 - junho de 1893). In: HAGINO, Rika. Considerações Sobre a Obra Nigorie (Enseada de Águas Turvas) e Sua Autora Higuchi Ichiyô (1872-1896). Tese de Mestrado, Universidade de São Paulo (USP) - Faculdade de Filosofia, Letras e Ciências Humanas (FFLCH), Departamento de Letras Orientais (DLO). São Paulo: 2007. Capítulo 2, subcapítulo 2.2, p. 37-42

HATORI, Tetsuya. Literatura Moderna Japonesa: a genealogia do anti-carreirismo. Anais do XII ENPULLCJ/II EEJ. Rio Grande do Sul: UFRGS, p. 31-46, 2001.

LAKOFF, Robin. Linguagem e lugar da mulher (1973). In: Organização e tradução Ana Cristina Ostermann, Beatriz Fontana. Linguagem. Gênero. Sexualidade: clássicos traduzidos. $1^{\mathrm{a}}$ ed. São Paulo: Parábola Editorial, 2010. Capítulo 2, p. 13-30. 
LECLERCQ, Laurence. As mulheres na produção literária japonesa contemporânea: uma atuação de destaque. Anais do IV CIEJB/XVIII ENPULLCJ. São Paulo: Centro de Estudos Japoneses - USP, p. 239-247, 2006.

MAGALHÃES, Isabel Allegro. Diferenças Sexuais na Escrita: ao contrário de Diotima. In CIEG (Centro Universitário de Estudos Germanisticos) - Actas do Colóquio "Escrita de Mulheres" - Coimbra: Universidade de Coimbra, 2004, n 19, p. 09-23.

SUZUKI, Tae. A Escrita Japonesa. Revista de Estudos Japoneses. São Paulo: Centro de Estudos Japoneses - USP, nº 5, p. 53-61, 1985.

TAKEHARA, Margarete Mitico. Introdução de Caminhos Opostos. In: Contos da Era Meiji. São Paulo: Centro de Estudos Japoneses da USP, 1993. p. 21-34.

OSTERMANN, Ana Cristina \& FONTANA, Beatriz. Linguagem, gênero, sexualidade: clássicos traduzidos. São Paulo: Parábola Editorial, 2009.

YOSHIDA, Luiza Nana. Kitchin e o fenômeno Banana. Revista de Estudos Japoneses. São Paulo: Centro de Estudos Japoneses- USP, nº 10, p. 57- 68, 1990.

YOSHIDA, Luiza Nana. A personagem feminina de Konjaku Monogatari - A juventude e a decrepitude. Revista de Estudos Japoneses. São Paulo: Centro de Estudos Japoneses USP, nº 12, p. 63-74, 1992.

YOSHIDA, Luiza Nana. A Época Clássica Japonesa e Suas Manifestações Literárias. Revista de Estudos Japoneses. São Paulo: Centro de Estudos Japoneses - USP, nº 19, p. 59-75, 1999. 